other names eg. 'blackout', 'five-minutes-in-heaven and 'space monkey'. Participants are usually adolescents - a North American study found $68 \%$ had heard of the game, $45 \%$ knew somebody who played it, $6.6 \%$ had tried it and $40 \%$ perceived no risk, although this is difficult to quantify. Warning signs include marks on neck, headaches, blood-shot eyes, changes in personality.

Social networking sites have enabled millions to watch videos of the choking game, which may normalise the behaviour. Most bunk beds are made using metal tubes or timbers, their design enabling easy attachment of ligatures.

Conclusion Adolescents must be made aware of the dangers of this activity and parents and professionals need to recognise the warning signs. There is the potential for bunk beds to be designed to eliminate anchoring points for ligatures.

\section{0-003 PSYCHOSOCIAL DEVELOPMENTAL TRAJECTORY OF YOUNG ADULTS BORN PRETERM IN THE NETHERLANDS}

${ }^{1} \mathrm{SM}$ van der Pal, ${ }^{2} \mathrm{H}$ Maurice-Stam, ${ }^{2} \mathrm{MA}$ Grootenhuis, ${ }^{3} \mathrm{AG}$ van Wassenaer-Leemhuis, ${ }^{1} \mathrm{KM}$ van der Pal-de Bruin. ' Child Health, TNO, Leiden, Netherlands; ${ }^{2}$ Pediatric Psychosocial Department, Emma Children's Hospital AMC, Amsterdam, Netherlands; ${ }^{3}$ Department of Neonatology, Emma Children's Hospital AMC, Amsterdam, Netherlands

10.1136/archdischild-2014-307384.70

Background and aims The study aimed to assess the psychosocial developmental trajectory of young adults who were born preterm, by comparing their trajectory with that of peers who receive disability benefits and of peers from the general population.

Methods Young adults from the POPS (Project On Preterm and Small for gestational age infants) cohort study, born in 1983 in the Netherlands, completed online the Course of Life Questionnaire (CoLQ - achievement of psychosocial developmental milestones) at 28 years of age $(n=300)$. Their scores were compared to the scores of 134 young adults who receive disability benefits (EMWAjong-group), and 211 age-matched peers from the general population (Ref-group), using analysis of variance and logistic regression analysis.

Results The POPS-group scored significantly lower than the Refgroup on Psychosexual Development (effect size -0.26, p < 0.01), Antisocial Behaviour (ES -0.44, p < 0.001) and Substance Use and Gambling (ES -0.35, p $<0.001$ ). Exploration on itemlevel revealed that the POPS-group had their first boyfriend/girlfriend at later age, were more often single, misbehaved less at school and smoked, drank and gambled less. On the scales Autonomy Development and Social Development no differences were found between the POPS-group and the Ref-group. However, the POPS-group scored significantly better than the EMWAjong-group on these scales.

Conclusions Young adults born preterm showed some psychosocial developmental trajectory delays and might benefit from support at teenage age, especially those receiving disability benefits. Because of non-response bias in the POPS-group the results might be an underrepresentation of the psychosocial developmental problems of young adults born preterm.

\section{0-004 SERUM FOLLISTATIN IN GIRLS WITH PUBERTAL HYPERANDROGENISM}

A Moskovkina, OZ Puzikova, VA Linde. Pediatric Gynecology, Rostov Scientific and Research Institute of Obstetrics and Pediatrics, Rostov-on-Don, Russia
The aim of the study was to examine the serum follistatin level in adolescent girls with hyperandrogenism (HA) and its possible role in the development of ovarian dysfunction.

Methods Follistatin, follicle-stimulating hormone (FSH), estradiol $\left(E_{2}\right)$ were studied in serum of 42 adolescent girls aged 1517 years with different clinical symptoms of HA (acne, hirsutism) and irregular menstrual cycle (IMC), 42 patients with regularmenstrual cycle (RMC) and 30 healthy adolescents.

Results Hyperandrogenic patients with IMC showed an increased follistatin secretion $(p$ ? $=0,03)$ compared to a group with RMC and control group. This fact points to the involvement of this glycoprotein in the pathogenesis of ovarian dysfunctionin girls' puberty. Also we found significant negative correlation between the levels of FSH and follistatin $(\mathrm{p}=0,02)$ that proved the inverse relationship between secretion of gonadotropins and follistatin level. Besides the negative correlation between follistatin and $\mathrm{E}_{2}$ has been revealed ( $\left.\mathrm{p}=0,04\right)$.

Conclusions It may be difficult to distinguish biologically and ultrasonically hyperandrogenic adolescents as the result of normalmaturational process of puberty from the ones with developing polycystic ovarian syndrome (PCOS). The increased secretion of follistatin and its correlation with the reduction of FSH and estradiol in adolescent girls with menstrual irregularities and hyperandrogenism confirms the pathological role of this intraovarian factor in discoordination of peripheral functioning of reproductive system, and its possible significance in pathogenesis of PCOS as a future outcome of pubertal hyperandrogenism.

\section{0-005 WITHDRAWN}

\section{0-005A ADOLESCENT CARE IN ICU: EUROPEAN SOCIETY OF PAEDIATRIC AND NEONATAL INTENSIVE CARE (ESPNIC) SURVEY}

R Tuckwell, D Wood, J Brierley. PICU, Great Ormond St Hospital, London, UK

\subsection{6/archdischild-2014-307384.72}

Background and aims Traditional healthcare services, often designed around adults and young children, under serve adolescents, who have distinct physical and psychological needs. The WHO-endorsed UK 'You're Welcome' Quality criteria for young people friendly health services (2011) has driven improvements, but it is unclear how these generic standards apply to the critically ill. Using an ICU-adapted version, we undertook a panEuropean baseline survey of current practice.

Methods Healthcare professionals and a past patient young people group selected 6 key areas: Privacy, Permission, DVT Prophylaxis, Personal life, Puberty and Practical issues (6Ps). A questionnaire regarding these $6 \mathrm{Ps} /$ related care was translated into 7 languages and distributed to ESPNIC members.

Results 70/358 (20\%) clinicians from 54 institutions responded across 16 countries. Young people $(<16$ years) mostly treated in PICUs; $18+$ in adult units; $16-18$ evenly split. For adolescents, $68 \%$ of hospitals undertake DVT prophylaxis, $50 \%$ have a privacy during care policy, but only $24 \%$ preferably allocate awake patients same-sex staff and 50\% remove catheters before patient awake. $90 \%$ routinely take social history, falling to $32 \%$ for sexual history and 54\% for recreational drug use. $63 \%$ undertake routine pregnancy testing and $89 \%$ seek consent from adolescents themselves if possible. 
Conclusions An ICU stay can have significant, long-lasting impacts on young people and their families. This is the first panEuropean survey to investigate ICU care for this group. We identified significant variation in adherence to quality standards. Some of this may be culturally influenced but there are also differences in less obviously controversial measures e.g. DVT prophylaxis. Further qualitative work is planned.

\section{Big Data Studies}

\section{0-006 FOLLOW - UP OUTCOMES FROM THE BOOST-II UK TRIAL OF OXYGEN SATURATION TARGETING IN PRETERM INFANTS}

B Stenson, P Brocklehurst, P Cairns, S Deshpande, BW Fleck, HL Halliday, E Juszzzak, A King, N Marlow, W Tin, S Wardle. BOOST II UK Collaborative Group, National Perinatal Epidemiology Unit, Oxford, UK

\subsection{6/archdischild-2014-307384.73}

Background and aims The optimal target range for pulse oximeter saturation $\left(\mathrm{SpO}_{2}\right)$ in extremely preterm infants is unknown. BOOST-II UK is one of 5 international studies that have recently investigated this.

Methods Preterm infants born before 28 weeks' gestation were randomised within $24 \mathrm{~h}$ of birth to an $\mathrm{SpO}_{2}$ target range of 85$89 \%$ or $91-95 \%$. The intervention used masked offset oximeters and was continued until 36 weeks' gestation. The primary outcome was a composite of death or serious neurosensory disability (SND) in survivors at age 2 corrected for prematurity, evaluated in 745 infants cared for using updated trial oximeters. A sensitivity analysis restricted to infants assessed by a Bayley III examination and a secondary analysis including a further 228 infants who were studied before the oximeters were updated were also performed.

Results The primary outcome was determined for 722 (96.9\%) of infants.

\begin{tabular}{|c|c|c|c|c|}
\hline & $\begin{array}{l}\text { Lower } \mathrm{SpO}_{2} \text { target } \\
(85-89 \%)\end{array}$ & $\begin{array}{l}\text { Higher } \mathrm{SpO}_{2} \text { target } \\
(91-95 \%)\end{array}$ & $\begin{array}{l}\text { Adjusted risk ratio } \\
\left(^{*}=95 \% \mathrm{Cl}, \dagger=99 \% \mathrm{Cl}\right)\end{array}$ & $P$ value \\
\hline Death or SND & $187 / 366(51.1 \%)$ & $165 / 356(46.3 \%)$ & $1.11(0.98-1.26)^{*}$ & 0.11 \\
\hline Death & $101 / 371(27.2 \%)$ & 69/369 (18.7\%) & $1.38(1.0-1.9) \dagger$ & 0.01 \\
\hline SND & $86 / 265(32.5 \%)$ & 96/287 (33.4\%) & $1.01(0.76-1.34) \dagger$ & 0.96 \\
\hline
\end{tabular}

The sensitivity analysis showed similar results. In the secondary analysis the mortality difference was $4.9 \%(\mathrm{p}=0.05)$. Severe visual loss did not differ between groups.

Conclusions The higher $\mathrm{SpO}_{2}$ target group had $8.5 \%$ greater survival with no increase in serious neurosensory disability. For infants born before 28 weeks" gestation, $\mathrm{SpO}_{2}$ targets below $90 \%$ are not recommended.

\section{0-007 NEONATAL HYPOGLYCEMIA: INTENSIVE TREATMENT OR EXPECTANT MONITORING?}

${ }^{1}$ AAMW van Kempen, ${ }^{2} \mathrm{PF}$ Eskes, ${ }^{3} \mathrm{JH}$ Kok, ${ }^{4} \mathrm{~N}$ Boluyt. ${ }^{1}$ Neonatology, OLVG Hospital, Amsterdam, Netherlands; ${ }^{2}$ Pediatrics, Meander Medical Center, Amersfoort, Netherlands; ${ }^{3}$ Neonatology, Emma Children's Hospital/AMC, Amsterdam, Netherlands; ${ }^{4}$ NA, National Health Care Institute, Diemen, Netherlands

10.1136/archdischild-2014-307384.74
Background The definition of neonatal hypoglycemia is still subject to discussion, resulting in a wide range of treatment protocols.

Objective To compare two expert-based management strategies at both ends of the current treatment-spectrum of 'moderate' neonatal hypoglycemia (plasma glucose $2.0-2.5 \mathrm{mmol} / \mathrm{l}$ ).

Design/methods Otherwise healthy, 'high-risk' newborns $\geq 35$ weeks and $\geq 2000$ gram with moderate hypoglycemia: premature, small- or large-for-gestational-age or infants of diabetic mothers, were randomised to an intensive treatment strategy (aiming at [glucose] $\geq 2.6 \mathrm{mmol} / \mathrm{l}$ ) or an expectant monitoring strategy (aiming at [glucose] $\geq 2.0 \mathrm{mmol} / \mathrm{l})$. Development was assessed at 18 months (corrected) age, using the Bayley Scales of Infant Development (BSID-III). The study was designed as a non-inferiority trial.

Results In $84 \%$ of the 691 enrolled infants the BSID-III was performed. Cognitive and motor outcomes were comparable in both treatment arms (Table). The results were similar in the overall analysis and in the subgroups.

\begin{tabular}{|c|c|c|c|}
\hline & Intensive Treatment & Expectant Monitoring & Mean Difference $(95 \% \mathrm{Cl})$ \\
\hline BSID-Cognitive & $103.6 \pm 10.9$ & $104.6 \pm 11.4$ & $1.0(-0.8 ;+2.8)$ \\
\hline BSID-Motor & $101.8 \pm 10.6$ & $101.6 \pm 11.7$ & $-0.2(-2.1 ;+1.6)$ \\
\hline
\end{tabular}

The plasma glucose concentration was higher in the intensive treatment group: $+0.24 \mathrm{mmol} / 1(+0.31 ;+0.16)$. Hypoglycemia episodes (after randomization) occurred more frequently in the expectant monitoring group (70\% vs. 57\%, p < 0.001). More infants in the intensive treatment group received additional feeding (94\% vs. $76 \%)$, tube-feeding (12\% vs. $4 \%)$ and/or intravenous glucose $(20 \%$ vs. $6 \%)$ (all: $\mathrm{p}<0.001)$.

Conclusion An expectant monitoring strategy is not inferior to intensive treatment with regard to developmental outcome at 18 months in otherwise healthy newborn infants $\geq 35$ weeks and $\geq 2000$ gram with moderate hypoglycemia.

\section{0-008 EARLY BIFIDOBACTERIUM BREVE BBG-001 TO PREVENT NECROTISING ENTEROCOLITIS, LATE-ONSET SEPSIS AND DEATH: THE PIPS TRIAL}

${ }^{1} \mathrm{KL}$ Costeloe, ${ }^{2} \mathrm{M}$ Wilks, ${ }^{3} \mathrm{P}$ Hardy, ${ }^{3} \mathrm{C}$ Nelis, ${ }^{2} \mathrm{MR}$ Millar. ${ }^{1}$ Paediatrics, Queen Mary University of London, London, UK; ${ }^{2}$ Microbiology, Barts Health NHS Trust, London, UK; ${ }^{3}$ National Perinatal Epidemiology Unit, University of Oxford, Oxford, UK

\subsection{6/archdischild-2014-307384.75}

Background Interpretation of published trials of probiotics in preterm infants is complicated by the use of multiple bacterial strains and exclusion from some trials of babies at high-risk of complications.

Objective To evaluate a single strain of Bifidobacterium breve in an unselected population of preterm infants.

Methods Multi-centre double blind Randomised Placebo Controlled Trial of Bifidobacterium breve BBG-001, 2.1 to $5.3 \times 10^{8}$ cfu daily, ( $B$ breve) in infants below $31 \mathrm{w}$ gestation randomised before $48 \mathrm{~h}$. Primary outcomes were necrotising enterocolitis (NEC) $\geq$ Bell stage 2, late onset sepsis (LOS) and death. Results are presented by intention to treat adjusted for sex, gestation and randomisation within $24 \mathrm{~h}$ and allowing for clustering of multiples. 